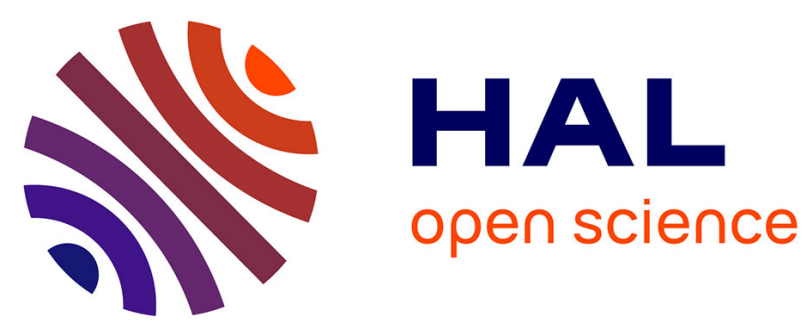

\title{
In situ measurements of ice saturation in young contrails
} Stefan Kaufmann, Christiane Voigt, Philipp Jessberger, Tina Jurkat, Hans Schlager, Alfons Schwarzenboeck, Marcus Klingebiel, Troy Thornberry

\section{To cite this version:}

Stefan Kaufmann, Christiane Voigt, Philipp Jessberger, Tina Jurkat, Hans Schlager, et al.. In situ measurements of ice saturation in young contrails. Geophysical Research Letters, 2014, 41 (2), pp.702709. hal-01981037

\section{HAL Id: hal-01981037 \\ https://hal.science/hal-01981037}

Submitted on 29 Nov 2021

HAL is a multi-disciplinary open access archive for the deposit and dissemination of scientific research documents, whether they are published or not. The documents may come from teaching and research institutions in France or abroad, or from public or private research centers.
L'archive ouverte pluridisciplinaire HAL, est destinée au dépôt et à la diffusion de documents scientifiques de niveau recherche, publiés ou non, émanant des établissements d'enseignement et de recherche français ou étrangers, des laboratoires publics ou privés. 


\section{Geophysical Research Letters}

\section{RESEARCH LETTER}

10.1002/2013GL058276

\section{Key Points:}

- Water vapor is detected in the UTLS with a novel water vapor mass spectrometer - Timescales for RHi relaxation to ice saturation in contrails are calculated

- In contrails, RHi shifts to ice saturation independent of ambient conditions

\section{Correspondence to:}

S. Kaufmann,

Stefan.Kaufmann@dlr.de

\section{Citation:}

Kaufmann, S., C. Voigt, P. Jeßberger, T. Jurkat, H. Schlager, A. Schwarzenboeck, M. Klingebiel, and T. Thornberry (2014), In situ measurements of ice saturation in young contrails, Geophys. Res. Lett., 41, 702-709, doi:10.1002/2013GL058276.

\section{Received 11 OCT 2013}

Accepted 28 DEC 2013

Accepted article online 4 JAN 2014

Published online 29 JAN 2014

\section{In situ measurements of ice saturation in young contrails}

\author{
Stefan Kaufmann ${ }^{1,2}$, Christiane Voigt ${ }^{1,2}$, Philipp Jeßberger ${ }^{1,2}$, Tina Jurkat ${ }^{1}$, Hans Schlager ${ }^{1}$, \\ Alfons Schwarzenboeck ${ }^{3}$, Marcus Klingebiel ${ }^{2}$, and Troy Thornberry ${ }^{4}$
}

${ }^{1}$ Institut für Physik der Atmosphäre, Deutsches Zentrum für Luft- und Raumfahrt, Wessling, Germany, ${ }^{2}$ Institut für Physik der Atmosphäre, Johannes-Gutenberg University, Mainz, Germany, ${ }^{3}$ LaMP, University Blaise Pascal, Clermont-Ferrand, France, ${ }^{4}$ Chemical Sciences Division, Earth System Research Laboratory, NOAA, Boulder, Colorado, USA

Abstract Relative humidity with respect to ice $(\mathrm{RHi})$ is a major factor controlling the evolution of aircraft contrails. High-resolution airborne $\mathrm{H}_{2} \mathrm{O}$ measurements in and near contrails were made at a rate of $4.2 \mathrm{~Hz}$ using the novel water vapor mass spectrometer AIMS- $\mathrm{H}_{2} \mathrm{O}$ with in-flight calibration during the CONtrail, volcano, and Cirrus ExpeRimenT (CONCERT) 2011. Three 2 min old contrails were sampled near $11 \mathrm{~km}$ altitude. Independent of the ambient supersaturation or subsaturation over ice, the mean of the RHi frequency distribution within each contrail is shifted toward ice saturation. This shift can be explained by the high ice surface area densities with corresponding $\mathrm{RHi}$ relaxation times on the order of $20 \mathrm{~s}$, which lead to the fast equilibration of $\mathrm{H}_{2} \mathrm{O}$ between the vapor and ice phase. Understanding the interaction of water vapor with ice particles is essential to investigate the life cycle of contrails and cirrus.

\section{Introduction}

In contrast to direct aircraft emissions such as $\mathrm{CO}_{2}$, the climate impact of contrails is dictated by the interaction between the exhaust plume and the atmospheric environment. A contrail can form when the SchmidtAppleman criterion is satisfied, which requires the plume to be saturated with respect to water for some time during the jet phase in the first second of lifetime [e.g., Schumann, 1996]. While water vapor from the engine dominates ice particle nucleation and growth during the very early contrail stage, further growth or evaporation of the ice particles inside the contrail is dependent upon the ambient $\mathrm{RHi}$. The environment therefore needs to be at least saturated with respect to ice for a long lived contrail to develop [Jensen et al., 1998a]. In that case, the contrail can alter the radiation budget of the atmosphere, generally considered to result in a positive net radiative forcing [Burkhardt and Kärcher, 2011; Schumann et al., 2013]. However, simulations and observations of $\mathrm{RHi}$ in young contrails and their immediate environment are difficult due to the strong dynamic activity in the aircraft vortices and the complex interaction between the gas phase, sulfate aerosols, soot [Kärcher and Yu, 2009], and ice particles [e.g., Heymsfield et al., 1998]. Due to usually short measurement times inside contrails, there is only a limited database on contrail RHi up to now. Furthermore, a contrail is anything but a homogeneous object, with varying properties on spatial scales from several $100 \mathrm{~m}$ down to microphysical scales. Our measurements can add an important piece to that data set by providing accurate high-resolution humidity data helping to improve our understanding of the processes of contrail formation and persistence which is essential to assess the climate impact of air traffic.

Inside a contrail, the phase equilibrium between water vapor and ice particles shifts $\mathrm{RHi}$ toward saturation due to condensation of $\mathrm{H}_{2} \mathrm{O}$ and evaporation of ice particles. In terms of water vapor-ice interaction, young contrails and natural cirrus primarily differ in particle number concentration, size distribution, and shape of the ice particles [Voigt et al., 2011; Gayet et al., 2012]. Korolev and Mazin [2003] calculated characteristic RHi relaxation times for natural cirrus and mixed phase clouds, dependent on the product of particle number concentration $N$ and mean radius $\bar{r}$ and the up- or downdraft speed of the air parcel, respectively. For natural cirrus, they found typical relaxation times ranging from a few minutes up to a few hours. Since particle number concentration in young contrails are generally one to two magnitudes higher (in the order of $100 \mathrm{~cm}^{-3}$ ) [see Voigt et al., 2010] compared to natural cirrus clouds, one would expect short RHi relaxation times on the order of some $10 \mathrm{~s}$ [Korolev and Mazin, 2003]. Hence, RHi inside the contrail should be very close to saturation. However, deviations from saturation inside young contrails may occur, caused, e.g., by vertical air motion, turbulence, and mixing with ambient air. In addition, the entrainment of the exhaust in the vortices, their 
descent, and dynamic mixing may cause the $\mathrm{RHi}$ in the plume to deviate from equilibrium [Sussmann and Gierens, 1999]. Their simulations suggest that $\mathrm{RHi}$ is inhomogeneously distributed in young contrails and depends on the exact location in the primary wing tip vortices (primary wake) or the more diffuse region above (secondary wake).

In this study, we present a detailed evaluation of RHi inside three different young contrails from two different Boeing 777 airliners and an Airbus A321 with ages between 90 and 140 s. The contrails were measured with the research aircraft Falcon operated by the Deutsches Zentrum für Luft- und Raumfahrt (DLR) [Voigt et al., 2010] during the CONtrail, volcano, and Cirrus ExpeRimenT (CONCERT 2011) campaign in September 2011. Airborne measurements in contrails of commercial aircraft with different ages were performed during five research flights over Europe. To evaluate the impact of contrails on relative humidity, RHi data are classified in observations inside the contrails and outside in vicinity of the contrails. We derive separate RHi distribution functions and compare the measurements with calculated timescales for RHi relaxation to ice saturation due to sublimation and condensation of ice particles. Finally, we compare our findings to previous RHi measurements in contrails.

\section{AIMS- $\mathrm{H}_{2} \mathrm{O}$ Mass Spectrometer}

Water vapor measurements in contrails were obtained with the mass spectrometer AIMS- $\mathrm{H}_{2} \mathrm{O}$, which provides accurate, high-frequency humidity data in the upper troposphere and lower stratosphere. While in the lower stratosphere, very small changes in gas phase water vapor have a direct climate impact [Solomon et al., 2010]; an important role of water vapor in the upper troposphere mainly arises from its ability to form ice particles. The main benefits of the new instrument are its genuine ability to assess low water vapor concentrations typical for the upper troposphere and lower stratosphere where current water vapor instruments show significant deviations. Here the mass spectrometer generally used for the detection of trace gas mixing ratios in the parts per billion to parts per trillion range is extended to higher mixing ratios in the parts per million range. The combination of an in-flight calibrated measurement and the high spatial resolution of around $50 \mathrm{~m}$ make the AIMS- $\mathrm{H}_{2} \mathrm{O}$ instrument well suited for water vapor measurements in young contrails and cirrus clouds. The instrument measures the $\mathrm{H}_{2} \mathrm{O}$ mixing ratio in a range between 0.5 and 250 ppmv with an overall accuracy of 8 to $15 \%$ and a sampling frequency of $4.2 \mathrm{~Hz}$. The measurement technique is based on direct ionization of ambient air [Thornberry et al., 2013] in a newly developed discharge ion source and the detection of hydronium hydrates $\left(\mathrm{H}_{3} \mathrm{O}^{+}\left(\mathrm{H}_{2} \mathrm{O}\right)\right.$ and $\left.\mathrm{H}_{3} \mathrm{O}^{+}\left(\mathrm{H}_{2} \mathrm{O}\right)_{2}\right)$ with a linear quadrupole mass spectrometer. To achieve high accuracy, the instrument is calibrated during flight with a water vapor standard produced using the catalytic reaction of hydrogen and oxygen on a Pt surface [Rollins et al., 2011]. With temperature and pressure data from the Falcon basic instrumentation (accuracy of $0.5 \mathrm{~K}$ and $0.5 \mathrm{hPa}$, respectively), consequent error propagation yields a maximum uncertainty of 11 to $18 \%$ for $\mathrm{RHi}$. However, the comparison with other water vapor instruments on board the Falcon suggests that the uncertainty is probably lower. The uncertainties in the $\mathrm{H}_{2} \mathrm{O}$ and temperature measurements each contribute roughly half of the overall uncertainty in RHi. The uncertainty in static pressure only has a minor influence.

Besides the AIMS- $\mathrm{H}_{2} \mathrm{O}$ instrument, $\mathrm{H}_{2} \mathrm{O}$ was also measured with the tunable diode laser system WARAN (WAter vapoR ANalyzer), which primarily consists of a commercial WVSSIl water vapor sensor (SpectraSensors Inc.). The instrument has a measurement range between 30 and 40,000 ppmv with an uncertainty between 25 and $5 \%$ which increases with lower concentrations. The time resolution is $0.4 \mathrm{~Hz}$.

For classification of the $\mathrm{RHi}$, we use nitric oxide (NO) measurements obtained with a chemiluminescence detector [Schlager et al., 1999] and measurements of aerosol optical extinction from a Polar Nephelometer [Crepel et al., 1997]. In this study, extinction and NO measurements are used to distinguish between measurement sequences inside contrails and ambient air around the contrail. Additionally, mean particle number concentrations $(N)$ and mean particle radii $(\bar{r})$ are calculated using the FSSP-300 (Forward Scattering Spectrometer Probe) (size range 0.2-38.6 $\mu \mathrm{m}$ ) [Borrmann et al., 2000] mounted under the right wing of the Falcon.

\section{Meteorology and Measurement Strategy}

In order to perform measurements in young contrails, we used European Centre for Medium-Range Weather Forecasts (ECMWF) data to identify potential flight routes where the Schmidt-Appleman criterion was likely to be satisfied [e. g., Schumann, 1996] and where RHi is close to saturation. The measurements were performed 

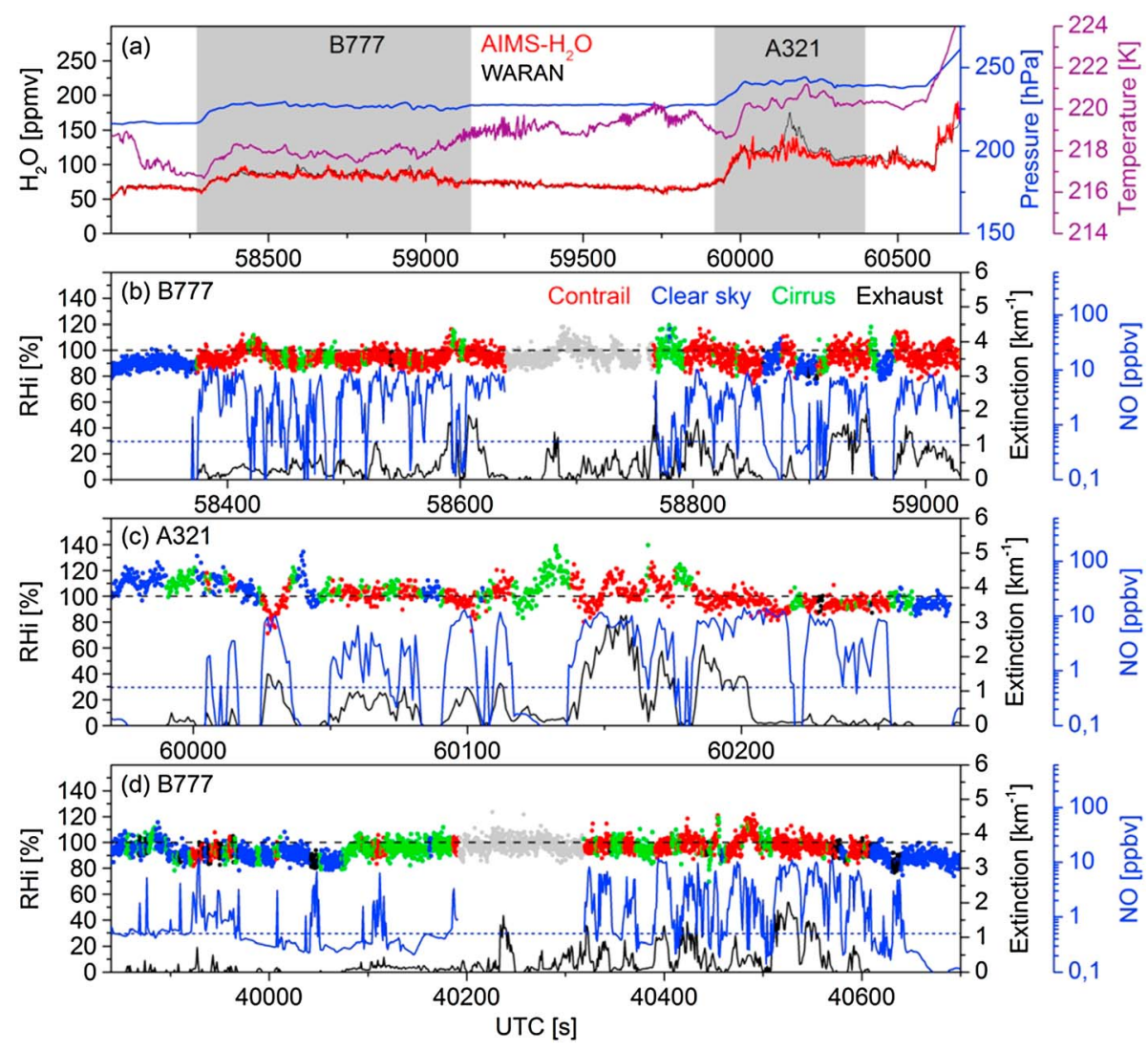

Figure 1. (a) Water vapor mixing ratios from AIMS- $\mathrm{H}_{2} \mathrm{O}$ (red) and WARAN (black) as well as pressure (blue) and temperature (purple) for a flight sequence on 16 September 2011. AIMS- $\mathrm{H}_{2} \mathrm{O}$ data are shown in $1 \mathrm{~Hz}$ resolution, WARAN data in $0.4 \mathrm{~Hz}$. Contrail chasing sequences are marked in grey. The large difference between AIMS- $\mathrm{H}_{2} \mathrm{O}$ and WARAN at $60150 \mathrm{~s}$ is a sampling artifact of WARAN's Rosemount inlet. (b-d) High-resolution RHi time series at $4.2 \mathrm{~Hz}$ from AIMS- $\mathrm{H}_{2} \mathrm{O}$ (colored dots), extinction (black line), and NO mixing ratio (blue line) for three measurement sequences in young contrails. RHi data are classified in contrail (red), clear Sky (blue), cirrus (green), and exhaust without contrail (black) using extinction and NO mixing ratio. The NO threshold of $0.5 \mathrm{ppbv}$ for identification of aircraft exhaust sequences is marked by the blue dotted line.

at a distance of roughly 20 to $30 \mathrm{~km}$ downstream of the contrail-generating aircraft, which corresponds to a contrail age of 90 to 140 s [Jurkat et al., 2011].

To avoid the heavy turbulence inside the primary wake of the aircraft, the Falcon slowly descended into the plumes from above. Figure 1a shows two measurement sequences with water vapor from the AIMS- $\mathrm{H}_{2} \mathrm{O}$ and WARAN, temperature, and pressure. We attempted to profile the aircraft wake in both horizontal and vertical directions, with the exception of the highly turbulent primary vortices. Therefore, we cannot assure that the measured data inside the contrail are fully representative of the complete exhaust plume.

\section{Classification of RHi Data}

Figure 1 shows three sequences of aircraft measurements in young contrails during CONCERT 2011. Figure 1a shows the time series of contrail observations from a B777 and a $\mathrm{A} 321$ aircraft on 16 September. $\mathrm{H}_{2} \mathrm{O}$ mixing ratios from AIMS- $\mathrm{H}_{2} \mathrm{O}$ (red) are shown in combination with static air temperature and pressure measurements from the Falcon basic instrumentation. WARAN $\mathrm{H}_{2} \mathrm{O}$ mixing ratios (black) agree with $\mathrm{AIMS}-\mathrm{H}_{2} \mathrm{O}$ data well within $10 \%$, except for the sampling artifact at $60,150 \mathrm{~s}$, which originates from evaporating ice particles in the WARAN's Rosemount inlet. Figures $1 \mathrm{~b}$ and $1 \mathrm{c}$ correspond to chasing sequences marked in Figure $1 \mathrm{a}$.

Figure 1d shows measurements in the plume of a different B777 made on 24 September. Measurements of aerosol extinction and NO mixing ratio were used to assign the RHi data to one of the following classes (color coded in Figure 1): contrail (red): extinction and NO both above threshold, clear sky (blue): extinction is zero and NO below threshold, natural cirrus or detrained ice crystals from the contrail (green): extinction 


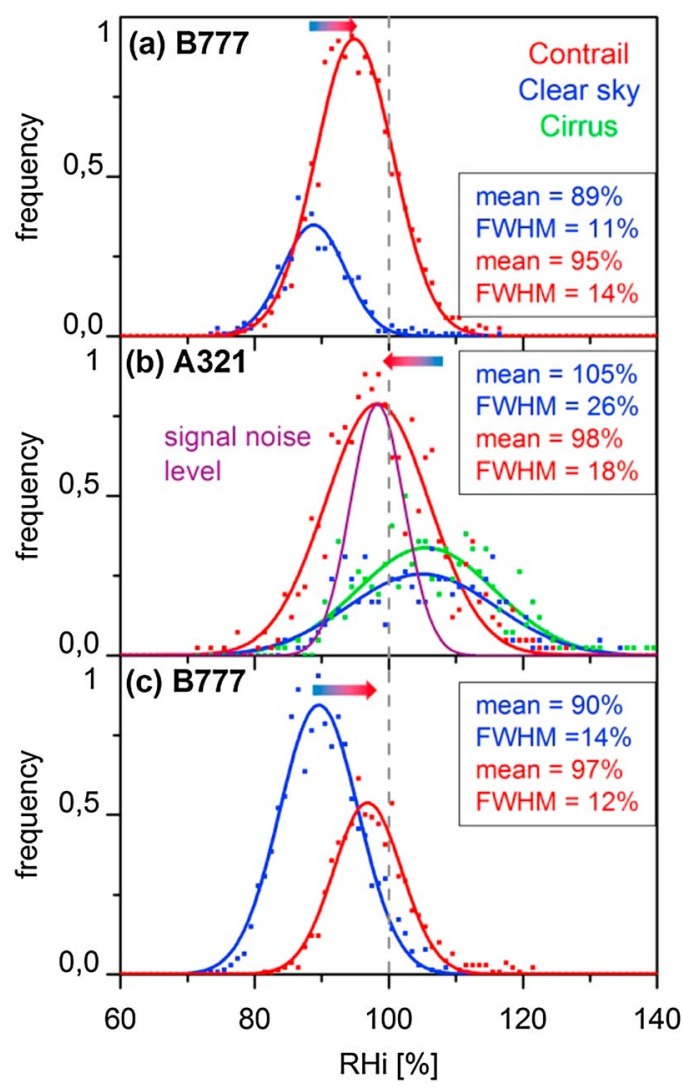

Figure 2. Frequency distribution of relative humidity with respect to ice for three different contrail sequences (full scale of the $y$ axis corresponds to a frequency of (a) 120, (b) 42, and (c) 120). Data points assigned to contrail (red), clear sky (blue), natural cirrus (green), and exhaust plumes without contrails (black) are shown as separate distribution functions. For all sequences, the distribution of $\mathrm{RHi}$ inside the contrail is shifted toward saturation compared to ambient conditions, independent whether the environment is subsaturated or supersaturated (indicated by the arrow). In Figure $2 \mathrm{~b}$, the signal noise level determined by the in-flight calibration is exemplarily shown (purple).

enhanced while NO below threshold, and exhaust without contrail (black): extinction is zero while NO above threshold, where the threshold value for NO is $0.5 \mathrm{ppbv}$. The data segments colored in grey could not be assigned to one of these classes.

\section{RHi Distribution and Altitude Profile}

In order to quantify the influence of the ice particles in the contrails on the RHi distribution, frequency distribution functions of the different classes for each of the three sequences are shown in Figure 2. For Figures $2 \mathrm{a}$ and $2 \mathrm{c}$, data indicate that the clear sky surroundings of the contrail were subsaturated with respect to ice with the distribution centered at $89 \%$ and $90 \%$, respectively. In contrast, the RHi distributions of cirrus and contrail measurements in these sequences are centered at $95 \%$ and $97 \%$, respectively. As expected, in the presence of ice particles the relative humidity is shifted toward saturation. The full width at half maximum (FWHM) of the distributions ranges from $11 \%$ for clear sky to $17 \%$ for cirrus. Taking a closer look at the vertical profiles of the sequences in Figures $3 a$ and $3 c$, the Falcon descended through subsaturated clear sky conditions. Below $11.0 \mathrm{~km}$ clear sky, cirrus and contrail air masses were sampled, alternating on a timescale of a few to several tens of seconds. In this altitude intervals, mean values of RHi inside cirrus and contrails are shifted toward saturation relative to the mean $\mathrm{RHi}$ of clear sky and exhaust. Considering only altitude intervals where the contrails are sampled, the shift in $\mathrm{RHi}$ is less pronounced than suggested in Figure 2 but still evident in each contrail altitude interval. The RHi distribution of the A321 contrail sequence (Figure 2b) exhibits different characteristics. For the contrail surroundings (clear sky and cirrus), the RHi distributions are centered above saturation at $105 \%$ and $106 \%$, respectively. Inside the contrail, $\mathrm{RHi}$ is shifted to lower values, with the distribution centered at $98 \%$ (red in Figure $2 \mathrm{~b}$ ). Both clear sky and cirrus distributions are rather wide, which 


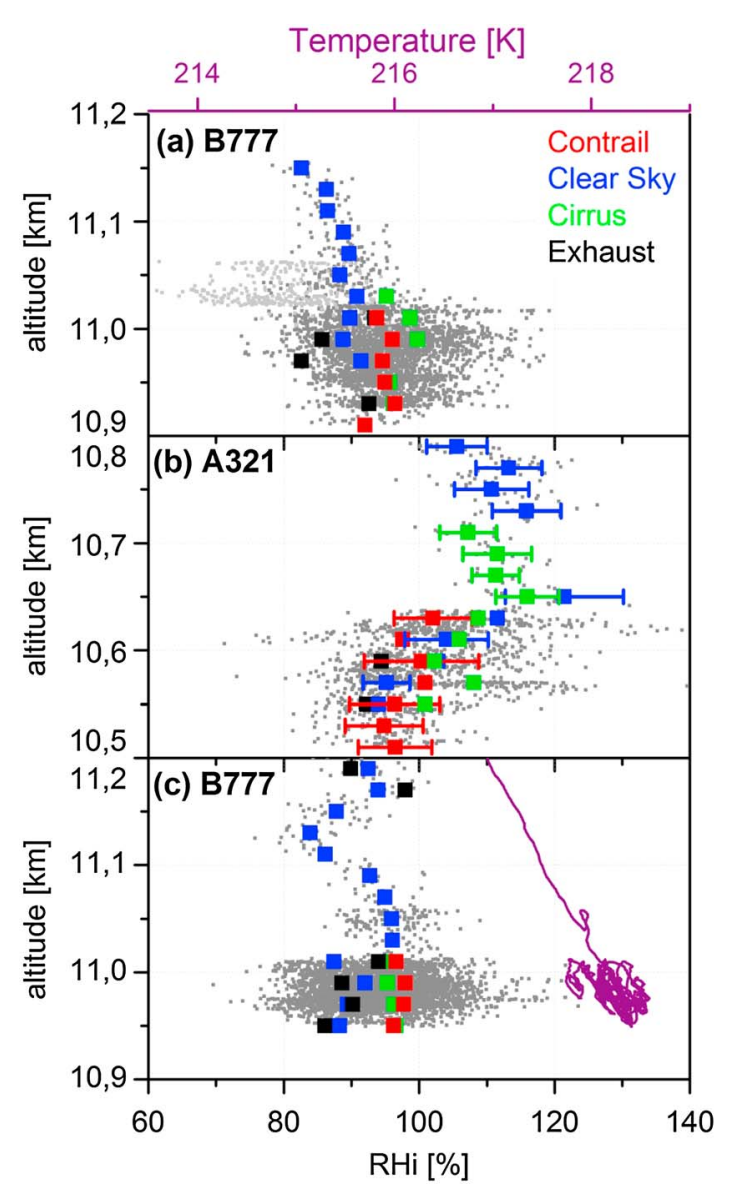

Figure 3. RHi profiles of the three contrail sequences (grey dots). Mean values for $20 \mathrm{~m}$ altitude bins have the same color code as in Figure 2. (b) Standard deviations for selected mean values. (c) Static air temperature during the measurement sequence. The general finding of $\mathrm{RHi}$ relaxation toward saturation inside the contrail is systematically observed at every altitude.

can be explained by the high variability of $\mathrm{RHi}$ with height. According to the profile for the A321 sequence (Figure 3b), the Falcon started in supersaturated clear sky conditions before descending into a cirrus at around $110 \% \mathrm{RHi}$. For all height intervals, $\mathrm{RHi}$ inside the contrail is shifted toward saturation relative to clear sky conditions. In that sequence, relaxation toward saturation in the contrail could be observed for both, subsaturated (e.g., $10.56 \mathrm{~km}$ ) and supersaturated (e.g., $10.63 \mathrm{~km}$ ), clear sky environments.

All three cases have in common that $\mathrm{RHi}$ inside the contrail is shifted toward ice saturation compared to the direct clear sky surroundings of the contrail. This finding is independent of whether the contrail environment is subsaturated or supersaturated.

The widths of the distribution functions in Figure 2 result from a superposition of natural variability and instrumental noise. To assess the contribution from natural variability to the observed width of the distributions, we include the purple Gaussian function in Figure $2 b$, which is an estimate of the signal noise derived from the inflight calibration. The standard deviation of the RHi signal during the in-flight calibration is $3.9 \%$, which is half of the standard deviation of the distribution function in the contrail of around 7.8\%. Assuming a Gaussian distribution of the natural RHi variation, one can deconvolve the measured distribution and the signal noise to estimate the width of the natural distribution function for the in-contrail measurements in Figure $2 b$ to be $6.7 \%$. With the precision of the measurement of around 4\%, the shift in the RHi distributions can be considered as significant.

\section{Estimation of RHi Relaxation Times}

The shift of RHi can be explained considering the short diffusion and relaxation times for $\mathrm{H}_{2} \mathrm{O}$ inside the contrail due to the presence of large numbers of small ice particles. The simplest way to estimate the characteristic relaxation times of $\mathrm{RHi}$ toward saturation inside the contrail is to assume a linear dependence of the 


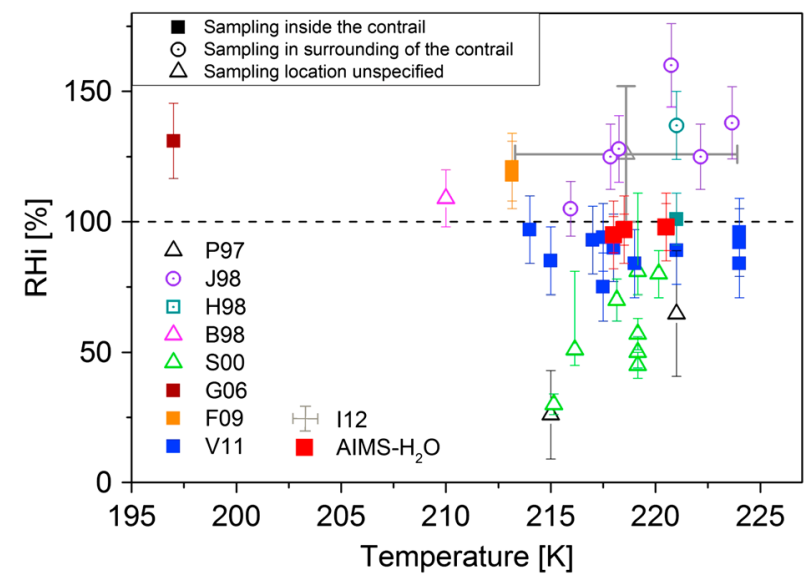

Figure 4. Collection of RHi measurements versus air temperature in contrails and in ambient air where contrails formed. Error bars mark the respective measurement uncertainty. Sources for these data are Petzold et al. [1997] (P97), Jensen et al. [1998a] (J98), Heymsfield et al. [1998] (H98), Baumgardner and Gandrud [1998] (B98), Schröder et al. [2000] (S00), Gao et al. [2006] (G06), Febvre et al. [2009] (F09), Voigt et al. [2011] (V11), and Iwabuchi et al. [2012] (112). For the latter, the cross stands for the standard deviation of a contrail climatology derived from satellite data. Open symbols are observations in ambient condition around the contrail or at unspecified sampling locations. For details about the different measurements see text. AIMS- $\mathrm{H}_{2} \mathrm{O}$ measurements of the three young contrail encounters during CONCERT 2011 are plotted in red. The small error bars represent the FWHM of the RHi distribution, the bigger ones represent the measurement uncertainty of a single data point.

rate of change in supersaturation $S(=\mathrm{RHi} / 100 \%-1)$ as $d S / d t=-\lambda S$, neglecting any external forcings (e.g., a collective updraft velocity). This yields $S=S_{0} \cdot e^{-\lambda t}$ with $S_{0}$ as the initial supersaturation or subsaturation. The parameter $\lambda$ represents the reciprocal time constant of the RHi relaxation by condensation or evaporation and is given by $\lambda=4 \pi D N r$ (based on Korolev and Mazin [2003]) where $D$ is the diffusion coefficient of $\mathrm{H}_{2} \mathrm{O}$ in air $\left(\mathrm{cm}^{2} / \mathrm{s}\right)$, $N$ is the ice crystal number concentration $\left(\mathrm{cm}^{-3}\right)$, and $\bar{r}$ is mean ice particle radius $(\mu \mathrm{m})$. For a temperature range between -80 and $40^{\circ} \mathrm{C}$, Hall and Pruppacher [1976] give $D=0.211\left(\frac{T}{T_{0}}\right)^{1.94}\left(\frac{p_{0}}{p}\right)$ as the empirical formula for the diffusion coefficient, with $T_{0}=273.15 \mathrm{~K}$ and $p_{0}=1013.25 \mathrm{hPa}$. For the measurement sequence in the A321 contrail (Figure 1c) we find mean values of $N=117 \mathrm{~cm}^{-3}$ and $\bar{r}=0.5 \mu \mathrm{m}$. Together with a mean pressure of 242 $\mathrm{hPa}$ and a mean temperature of $220 \mathrm{~K}$, the relaxation time constant of RHi can be estimated as $\tau=1 / \lambda \cong 23 \mathrm{~s}$. Since mean particle radii are small compared to previous studies [e.g.,Voigt et al., 2010], the calculated value for $\tau$ may be seen as upper estimate. However, all parameters, especially $N$ and $\bar{r}$, are inhomogeneously distributed within the contrail and influenced by local up- or downdrafts beyond the resolution of our measurements. Furthermore, $N$ decreases and $\bar{r}$ increases with plume age due to plume dilution and entrainment of ambient water vapor into the contrail. Despite the simplification by our quasisteady state approach, the RHi relaxations time is slightly higher than values of 1 to $10 \mathrm{~s}$ calculated with a more complex parcel model by Jensen et al. [1998b]. So $\tau$ is still by a factor of 5 lower than the plume ages of 90 to 140 $\mathrm{s}$; thus, one would indeed expect that $\mathrm{RH}$ inside the contrail is almost completely relaxed toward saturation.

\section{Discussion and Outlook}

In order to discuss our measurements within the context of previous studies, RHi data collected during different contrail sampling missions are summarized in Figure 4. Differences to ice saturation inside the contrail could be caused by sampling in different environments, in different parts of the dynamically active contrail, by biases in the measurements of humidity or temperature, or uncertainties in data evaluation. Since most studies on contrails have focused on contrail microphysics, relative humidity has often been treated as a constant parameter during a contrail measurement sequence, which renders a direct comparison difficult and may introduce a bias on the data shown in Figure 4. There are only a few cases where RHi time series are directly given. For example, Heymsfield et al. [1998] observe a shift of RHi from 136\% in ambient air toward saturation inside a several minutes old contrail generated and sampled by the NASA DC-8 aircraft.

Baumgardner and Gandrud [1998] report slightly supersaturated conditions for a $1 \mathrm{~s}$ old contrail; hence, equilibrium may not yet be reached. Petzold et al. [1997] also show observations of $1 \mathrm{~s}$ old contrails in strongly 
ice-subsaturated ambient air, which may indicate very short-lived contrails. Jensen et al. [1998a] report a variety of contrail measurements including short-lived contrails in supersaturated ambient air. Contrail formation in vertically narrow layers of humid air could explain these observations. When the ice crystals grow, they sediment in dry layers and sublimate. Schröder et al. [2000] and Febvre et al. [2009] treat RHi as constant parameter, likely because of a low resolution of $\mathrm{H}_{2} \mathrm{O}$ measurement. Voigt et al. [2011] report on an extensive data set of airborne measurements in young contrails where the RHi values inside the contrails were close to saturation but within the measurement uncertainty systematically subsaturated. Using a fraction of that data set, Jeßberger et al. [2013] and Gayet et al. [2012] have difficulties in reconciling the ice water content in individual contrails with the observed humidities. In a different approach, Iwabuchi et al. [2012] used satellite data from the Moderate Resolution Imaging Spectroradiometer (MODIS) and the Cloud-Aerosol Lidar and Infrared Pathfinder Satellite Observations (CALIPSO) to derive a contrail climatology for 2007 and 2009. They find mostly supersaturated conditions at the contrail tops. Gao et al. [2006] measured the contrail of the NASA WB-57 at very low temperatures $(T=197 \mathrm{~K})$. At those temperatures $\mathrm{RHi}$ above ice saturation inside the contrail could be explained by partial coating of the ice particles with a nitric acid containing particle phase as suggested from observations of condensed reactive nitrogen species.

Compared to these previous studies, the RHi values inside the contrails at temperatures around $218 \mathrm{~K}$ presented here are consistently very close to ice saturation. The small error bars on the AIMS data points in Figure 4 indicate the standard deviation of the in-contrail data set, while the larger bars represent the upper estimate of the measurement uncertainty. In contrast to the study of Sussmann and Gierens [1999], who did not see any secondary wake in numerical simulation for conditions with only $2 \%$ subsaturation, we repeatedly observed secondary wake contrails in environments with around $10 \%$ subsaturation, as in sequences in Figures $2 \mathrm{a}, 2 \mathrm{c}, 3 \mathrm{a}$, and 3c. For these sequences, $\mathrm{RHi}$ is shifted toward higher values inside the contrail, which is a clear indication that a secondary wake contrail in subsaturated environment is rather a natural feature than a measurement bias. Consistent with previous measurements in young contrails [e.g., Kübbeler et al., 2011; Jeßberger et al., 2013; Schumann et al., 2013], this broadens the range of atmospheric conditions where secondary wake contrails can form.

The first measurements of the novel water vapor mass spectrometer $\mathrm{AIMS}-\mathrm{H}_{2} \mathrm{O}$ with in-flight calibration proved that the instrument is well suited for humidity measurements under contrail conditions. We conclude that $\mathrm{RH}$ inside the contrails is relaxed to saturation which means that the gas phase $\mathrm{H}_{2} \mathrm{O}$ is in equilibrium with the saturation mixing ratio at ice particle surface. Short relaxation times of $23 \mathrm{~s}$ are expected by a simple estimation of RHi relaxation and caused by the high-number density of small ice particles and thus a large effective ice surface leading to short gas phase diffusion times inside the young contrail. For the first time, we were able to observe the relaxation process toward saturation in contrails embedded in both subsaturated and supersaturated environments during the same flight. Under these conditions, young contrails could be used as an atmospheric laboratory to assess the quality of RHi measurements. Large differences in RHi measurements reported in previous studies emphasize the importance for a detailed investigation of the interaction between water vapor and ice when studying microphysical processes inside contrails.

\section{Acknowledgments}

The campaign CONCERT 2011 was organized by the HGF-young investigator group AEROTROP (VH-NG-309, http:// www.pa.op.dlr.de/AEROTROP). Part of this work was funded by contract V01504/2-1 within the DFG SPP HALO 1294 and by the DLR project WeCare. We are thankful to $S$. Borrmann for providing and W. Frey and S. Molleker for operating the FSSP during CONCERT. We thank the DLR flight department and DFS for excellent support during the campaign and B. Kärcher for helpful comments on the manuscript.

The Editor thanks two anonymous reviewers for their assistance in evaluating this paper.

\section{References}

Baumgardner, D., and B. E. Gandrud (1998), A comparison of the microphysical and optical properties of particles in an aircraft contrail and mountain wave cloud, Geophys. Res. Lett., 25, 1129-1132, doi:10.1029/98GL00035.

Borrmann, S., A. Thomas, V. Rudakov, V. Yushkov, B. Lepuchov, T. Deshler, N. Vinnichenko, V. Khattatov, and L. Stefanutti (2000), Stratospheric aerosol measurements in the Arctic winter of 1996/1997 with the M-55 Geophysika high-altitude research aircraft, Tellus B, 52, 1088-1103, doi:10.1034/j.1600-0889.2000.00100.x.

Burkhardt, U., and B. Kärcher (2011), Global radiative forcing from contrail cirrus, Nat. Clim. Change, 1, 54-58, doi:10.1038/nclimate1068.

Crepel, O., J. F. Gayet, J.-F. Fournol, and S. Oshchepkov (1997), A new airborne polar nephelometer for the measurement of optical and microphysical cloud properties part 2, Preliminary tests, Ann. Geophys. Atmos. Hydrospheres Space Sci., 15, 460-470, doi:10.1007/s00585997-0460-0.

Febvre, G., J. F. Gayet, A. Minikin, H. Schlager, V. Shcherbakov, O. Jourdan, R. Busen, M. Fiebig, B. Kärcher, and U. Schumann (2009), On optical and microphysical characteristics of contrails and cirrus, J. Geophys. Res., 114, D02204, doi:10.1029/2008JD010184.

Gao, R. S., et al. (2006), Measurements of relative humidity in a persistent contrail, Atmos. Environ., 40, 1590-1600, doi:10.1016/j. atmosenv.2005.11.021.

Gayet, J. F., et al. (2012), The evolution of microphysical and optical properties of an A380 contrail in the vortex phase, Atmos. Chem. Phys., 12, 6629-6643, doi:10.5194/acp-12-6629-2012.

Hall, W. D., and H. R. Pruppacher (1976), The survival of ice particles falling from cirrus clouds in subsaturated air, J. Atmos. Sci., 33, 1995-2006, doi:10.1175/1520-0469(1976)033<1995:tsoipf $>2.0$. co;2. 
Heymsfield, A. J., R. P. Lawson, and G. W. Sachse (1998), Growth of ice crystals in a precipitating contrail, Geophys. Res. Lett., 25, 1335-1338, doi:10.1029/98GL00189.

Iwabuchi, H., P. Yang, K. N. Liou, and P. Minnis (2012), Physical and optical properties of persistent contrails: Climatology and interpretation, J. Geophys. Res., 117, D06215, doi:10.1029/2011JD017020.

Jensen, E. J., O. B. Toon, S. Kinne, G. W. Sachse, B. E. Anderson, K. R. Chan, C. H. Twohy, B. Gandrud, A. Heymsfield, and R. C. Miake-Lye (1998a), Environmental conditions required for contrail formation and persistence, J. Geophys. Res., 103, 3929-3936, doi:10.1029/97JD02808.

Jensen, E. J., O. B. Toon, R. F. Pueschel, J. Goodman, G. W. Sachse, B. E. Anderson, K. R. Chan, D. Baumgardner, and R. C. Miake-Lye (1998b), Ice crystal nucleation and growth in contrails forming at low ambient temperatures, Geophys. Res. Lett., 25, 1371-1374, doi:10.1029/ 97GL03592.

Jeßberger, P., C. Voigt, U. Schumann, I. Sölch, H. Schlager, S. Kaufmann, A. Petzold, D. Schäuble, and J.-F. Gayet (2013), Aircraft type influence on contrail properties, Atmos. Chem. Phys. Discuss., 13, 13,915-13,966, doi:10.5194/acpd-13-13915-2013.

Jurkat, T., C. Voigt, F. Arnold, H. Schlager, J. Kleffmann, H. Aufmhoff, D. Schäuble, M. Schaefer, and U. Schumann (2011), Measurements of HONO, NO, NOy and SO2 in aircraft exhaust plumes at cruise, Geophys. Res. Lett., 38, L10807, doi:10.1029/2011GL046884.

Kärcher, B., and F. Yu (2009), Role of aircraft soot emissions in contrail formation, Geophys. Res. Lett., 36, L01804, doi:10.1029/2008GL036649.

Korolev, A. V., and I. P. Mazin (2003), Supersaturation of water vapor in clouds, J. Atmos. Sci., 60, 2957-2974, doi:10.1175/1520-0469(2003) $060<2957:$ SOWVIC $>2.0 . C O ; 2$.

Kübbeler, M., et al. (2011), Thin and subvisible cirrus and contrails in a subsaturated environment, Atmos. Chem. Phys., 11, 5853-5865, doi:10.5194/acp-11-5853-2011.

Petzold, A., et al. (1997), Near-field measurements on contrail properties from fuels with different sulfur content, J. Geophys. Res., 102, 29,867-29,880, doi:10.1029/97JD02209.

Rollins, A. W., T. D. Thornberry, R.-S. Gao, B. . D. Hall, and D. W. Fahey (2011), Catalytic oxidation anf $\mathrm{H}_{2}$ on platinum: A robust method for generating low mixing ratio $\mathrm{H}_{2} \mathrm{O}$ standards, Atmos. Meas. Tech., 4, 2059-2064.

Schlager, H., P. Schulte, F. Flatoy, F. Slemr, P. van Velthoven, H. Ziereis, and U. Schumann (1999), Regional nitric oxide enhancements in the North Atlantic flight corridor observed and modeled during POLINAT 2-A case study, Geophys. Res. Lett., 26, 3061-3064, doi:10.1029/ 1999GL900349.

Schröder, F., B. Kärcher, C. Duroure, J. Ström, A. Petzold, J.-F. Gayet, B. Strauss, P. Wendling, and S. Borrmann (2000), On the transition of contrails into cirrus clouds, J. Atmos. Sci., 57, 464-480, doi:10.1175/1520-0469(2000)057<0464:ottoci>2.0.c0;2.

Schumann, U. (1996), On conditions for contrail formation from aircraft exhaust, Meteorol. Z., 5, 395-414.

Schumann, U., P. Jeßberger, and C. Voigt (2013), Contrail ice particles in aircraft wakes and their climatic importance, Geophys. Res. Lett., 40, 2867-2872, doi:10.1002/grl.50539.

Solomon, S., K. H. Rosenlof, R. W. Portmann, J. S. Daniel, S. M. Davis, T. J. Sanford, and G.-K. Plattner (2010), Contributions of stratospheric water vapor to decadal changes in the rate of global warming, Science, 327, 1219-1223, doi:10.1126/science.1182488.

Sussmann, R., and K. M. Gierens (1999), Lidar and numerical studies on the different evolution of vortex pair and secondary wake in young contrails, J. Geophys. Res., 104, 2131-2142, doi:10.1029/1998JD200034.

Thornberry, T. D., A. W. Rollins, R. S. Gao, L. A. Watts, S. J. Ciciora, R. J. McLaughlin, C. Voigt, B. Hall, and D. W. Fahey (2013), Measurement of low-ppm mixing ratios of water vapor in the upper troposphere and lower stratosphere using chemical ionization mass spectrometry, Atmos. Meas. Tech., 6, 1461-1475, doi:10.5194/amt-6-1461-2013.

Voigt, C., et al. (2010), In-situ observations of young contrails-Overview and selected results from the CONCERT campaign, Atmos. Chem. Phys., 10, 9039-9056, doi:10.5194/acp-10-9039-2010.

Voigt, C., U. Schumann, T. Jurkat, A. Petzold, J.-F. Gayet, M. Krämer, T. Thornberry, and D. W. Fahey (2011), Extinction and optical depth of contrails, Geophys. Res. Lett., 38, L11806, doi:10.1029/2011GL047189. 